\title{
Desenvolvimento de uma situação desencadeadora de aprendizagem do conceito de ângulo por meio de quatro ações de estudo davidovianas em um contexto de formação inicial de professores
}

\author{
Development of a triggering learning situation of the concept of \\ angle through four study actions by Davydov in an initial teacher \\ education context
}

\author{
Josélia Euzébio da Rosa ${ }^{1}$ \\ Frank Becker ${ }^{2}$
}

\begin{abstract}
RESUMO
A presente pesquisa, de natureza experimental, objetivou investigar o desenvolvimento do pensamento matemático em nível teórico, mediado pelo conceito de número, a partir da grandeza ângulo. Um Experimento Didático Desenvolvimental foi realizado com estudantes do Curso de Pedagogia. A dialética foi adotada como método de ensino e de pesquisa. Buscou-se desenvolver uma síntese histórica dos conceitos matemáticos a partir de Situações Desencadeadoras de Aprendizagem. Nesse sentido, indícios de desenvolvimento do pensamento matemático em nível teórico foram reunidos. Os resultados evidenciam a necessidade e algumas possibilidades de ressignificação do modo de organização do ensino no contexto da formação inicial de professores pesquisado.
\end{abstract}

Palavras-chave: Teoria Histórico-Cultural. Formação Inicial de Professores. Educação Matemática. Pedagogia.

\begin{abstract}
This research has experimental nature, and its aim at investigating development of mathematical thinking at the theoretical level mediated by the concept of number from the angle greatness. A Developmental Didactic Experiment was carried out with students of Pedagogy faculty. Dialectic was adopted as teaching and research method. Therefore, the research searched for develop a historical synthesis of mathematical concepts through triggering learning situations. In this sense, evidence on development of mathematical thinking were gathered. Results made evident the need and some possibilities of resignification on the teaching organization way within the researched initial teacher training.
\end{abstract}

Keywords: Historical-Cultural Theory. Initial teacher training. Mathematical Education. Pedagogy.

\footnotetext{
${ }^{1}$ Doutora em Educação pela Universidade Federal do Paraná (UFPR). Professora do Programa de Pós-Graduação em Educação e do curso de Pedagogia da Universidade do Sul de Santa Catarina (UNISUL). Orcid: https://orcid.org/0000-0001-5738-8518. E-mail: joselia.euzebio@yahoo.com.br. 2 Especialista em Inovação na Educação pela Universidade do Sul de Santa Catarina (UNISUL). Orientador Educacional do município de Balneário Gaivota. Orcid: https://orcid.org/0000-00015182-2213. E-mail: frankbecker@outlook.com.br.
} 


\section{Contexto coletivo de investigação}

O presente artigo faz parte de um projeto coletivo mais amplo, desenvolvido no contexto de um Grupo de Pesquisa ${ }^{3}$ que tem como finalidade refletir sobre as limitações do modo de organização do ensino vigente no Brasil e suas possibilidades de superação a partir dos fundamentos e desdobramentos da Teoria HistóricoCultural. Na especificidade da disciplina de Matemática, por exemplo, atualmente predomina o desenvolvimento do pensamento empírico, em detrimento do pensamento teórico (ROSA; MATOS, 2018).

De acordo com Davídov (2017), o pensamento empírico não condiz com o estágio atual de desenvolvimento da ciência contemporânea. Na atualidade, a tarefa da escola consiste em "[...] ensinar os alunos a pensar; ou seja, desenvolver ativamente neles os fundamentos do pensamento contemporâneo para o qual é necessário organizar um ensino que impulsione o desenvolvimento" (DAVÍDOV, 1988, p. 3).

Ao assumir a tarefa da escola proposta por Davídov (1988) como nossa, e conduzidos pelos pressupostos teóricos supracitados, surgiram alguns questionamentos: como tornar os fundamentos teóricos estudados uma realidade no ensino? Como concretizar tais fundamentos? Enfim, queríamos saber como fazer e como colocar a teoria em prática. Era realmente a palavra como que nos perseguia e por isso a incorporamos em nosso problema de pesquisa coletivo: como organizar o ensino de Matemática com potencialidades para promover a aprendizagem de conceitos científicos e o desenvolvimento do pensamento teórico nos diferentes níveis de ensino?

É importante ressaltar que a palavra como, aqui concebida, está de acordo com os fundamentos teóricos anunciados. Desse modo, a resposta teórica ao problema anunciado requer um modo geral de organização do ensino, objetivado em uma experiência particular, e não uma sequência de procedimentos, tal como procede o pensamento empírico. Nossas pesquisas ocorrem nos diversos níveis de escolarização, desde a Educação Básica até o Ensino Superior. Contudo, no

\footnotetext{
${ }^{3}$ TedMat - Grupo de Pesquisa Teoria do Ensino Desenvolvimental (UNISUL). O referido grupo, juntamente com o GEPMAHC - Grupo de Pesquisa em Educação Matemática: uma abordagem Histórico-Cultural (UNESC), faz parte da Unidade Catarinense da rede nacional de grupos de pesquisa intitulada GEPAPe - Grupo de Estudos e Pesquisas sobre a Atividade Pedagógica (USP).
} 
presente artigo, apresentamos os resultados de uma investigação que realizamos na formação inicial de professores, no contexto do Curso de Pedagogia de uma universidade localizada no sul do estado de Santa Catarina, Brasil.

Portanto, no processo de busca por respostas ao problema de pesquisa coletivo, no contexto da formação inicial de professores, tomamos como fio condutor o seguinte objetivo geral: investigar o desenvolvimento do pensamento matemático, em nível teórico, por estudantes de um curso de Pedagogia.

\section{Método e Metodologia}

Em consonância com os fundamentos da Teoria Histórico-Cultural, o método que sustenta nossas ações de pesquisa, ensino e extensão é a dialética materialista. Uma das principais características desse método consiste na premissa de que o fenômeno investigado é considerado em sua totalidade, na indissociabilidade entre teoria e prática.

A metodologia de pesquisa adotada foi o Experimento Didático Desenvolvimental, atrelada à compreensão de que é pelo ensino que se aprende e, por consequência, se desenvolve. Porém, não se trata de qualquer ensino, mas aquele organizado com base nos conteúdos e métodos que possibilitem a promoção do desenvolvimento do pensamento teórico nos estudantes (crianças, adolescentes, jovens e adultos) a partir da apropriação de conhecimentos científicos.

Essa metodologia de pesquisa proposta por Davídov (1988) permite ao pesquisador investigar o desenvolvimento dos seres humanos no processo de ensino e aprendizagem. De acordo com Davídov (1988), o Experimento Didático Desenvolvimental caracteriza-se pela intervenção ativa do pesquisador nos processos que ele investiga. Assim, difere-se essencialmente do experimento de constatação, que destaca somente o estado já formado e presente nos estudantes.

Essa proposta de "investigação aparece como metodologia de educação e ensino experimentais que impulsionam o desenvolvimento" (DAVÍDOV, 1988, p. 196). A realização do Experimento Didático Desenvolvimental pressupõe a projeção e modelação da relação essencial dos conceitos no processo de aprendizagem. Durante a investigação, no contexto do processo de 
aprendizagem, também se estuda o movimento de origem e desenvolvimento de novos conceitos e sistemas conceituais.

\section{O experimento didático}

Realizado ao longo de um semestre (2020-2), o Experimento Didático Desenvolvimental contou com trinta e quatro acadêmicos do quarto e sexto semestres do Curso de Pedagogia, matriculados na Unidade de Aprendizagem (disciplina) Fundamentos e Metodologias de Matemática para os Anos Iniciais do Ensino Fundamental.

Do ponto de vista da idade, trata-se de um grupo bem diversificado, com estudantes de todas as idades, desde 18 até 48 anos.

As aulas foram realizadas nas terças-feiras, das 19h15min até as 22h30min, via plataforma Zoom, em função da pandemia causada pelo vírus SARS-CoV-2. Além dos trinta e quatro acadêmicos, também participaram do experimento quinze pesquisadores do TedMat, na condição de docente/pesquisador. As aulas foram gravadas no próprio aplicativo e disponibilizadas para os estudantes e pesquisadores. Ao todo, foram quinze encontros e, em cada qual, um pesquisador assumiu a docência compartilhada com a professora titular.

Durante as aulas, os sistemas conceituais matemáticos foram desenvolvidos a partir de Situações Desencadeadoras de Aprendizagem em consonância com a Atividade Orientadora de Ensino (MOURA, 1996).

A Atividade Orientadora de Ensino constitui-se um modo geral de organização do ensino, em que seu conteúdo principal é o conhecimento teórico e seu objeto é a constituição do pensamento teórico do indivíduo no movimento de apropriação do conhecimento. Assim, o professor, ao organizar ações que objetivam o ensinar, também requalifica seus conhecimentos, e é esse processo que caracteriza a Atividade Orientadora de Ensino como unidade de formação do professor e do estudante (MOURA et al., 2016, p. 115).

Como proposta teórico-metodológica, a Atividade Orientadora de Ensino contém, em sua estrutura, a síntese histórica do conceito, os recursos didáticos, a análise e a síntese coletiva durante a realização de Situações Desencadeadoras de Aprendizagem, que, por sua vez, consistem em uma proposta organizada pelo 
professor que, com base em seus objetivos de ensino, conduz o movimento conceitual a ser apropriado a partir de problemas desencadeadores.

$\mathrm{Na}$ situação desencadeadora de aprendizagem há a apresentação do problema que visa evidenciar a necessidade social do homem em produzir determinado conhecimento. Os modos de ação correspondentes a tais ações podem conformar se em histórias virtuais, jogos e situações emergentes do cotidiano, por exemplo (ARAUJO, 2019, p. 134).

Em outras palavras, a "situação desencadeadora de aprendizagem contém um problema desencadeador" (OLIVEIRA; PANOSSIAN, 2020, p. 7). Dentre os principais tipos de Situação Desencadeadora de Aprendizagem, optamos pela História Virtual do Conceito. Histórias Virtuais configuram-se como:

Situações-problema colocadas por personagens de histórias infantis, lendas ou da própria história da matemática como desencadeadoras do pensamento da criança de forma a envolvê-la na produção da solução do problema que faz parte do contexto da história. Dessa forma, contar, realizar cálculos, registrá-los poderá tornar-se para ela uma necessidade real (MOURA, 1996, p. 20).

Em nosso experimento didático, durante a solução de cada Situação Desencadeadora de Aprendizagem (tarefa de estudo) ${ }^{4}$, foram desenvolvidas as quatro ações de estudo propostas por Davídov (1982).

A tarefa de estudo que o professor propõe aos estudantes, na especificidade do ensino de Matemática, exige deles a análise das relações entre grandezas, durante o experimento objetal, a fim de revelar a relação essencial que será abstraída por meio do processo de modelação.

Durante a solução da tarefa, os alunos identificam a origem do 'núcleo' do objeto integral estudado e, utilizando-a, reproduzem mentalmente este objeto. Com isso, ao resolver a tarefa, os estudantes completam uma espécie de micro-ciclo de ascensão do abstrato ao concreto como meio de assimilação dos conhecimentos teóricos (DAVÍDOV, 1988, p. 179).

\footnotetext{
4 Concebemos uma Situação Desencadeadora de Aprendizagem como tarefa de estudo quando contempla, durante o processo de solução, as ações de estudo de Davídov (1988).
} 
De acordo com Davídov (1988, p. 148), os processos de redução e ascensão "se encontram em unidade", nesta, o procedimento de redução do concreto ao abstrato aparece como "momento subordinado" ao procedimento de ascensão do abstrato ao concreto. Neste movimento, durante o desenvolvimento da tarefa de estudo, "o pensamento dos escolares se move do geral ao particular" (DAVÍDOV, 1988, p. 179).

Diante da impossibilidade de abarcar todo o Experimento Didático Desenvolvimental nos limites de um artigo, elegemos uma unidade de análise que consiste na essência dessa totalidade: o desenvolvimento do pensamento matemático, em nível teórico, por acadêmicos do Curso de Pedagogia.

A título de exemplificação, no presente artigo, apresentamos a Situação Desencadeadora Desenvolvida a partir da grandeza ângulo durante duas aulas com início às $19 \mathrm{~h} 15 \mathrm{~min}$ e término às 22h30min. Trata-se de um isolado (CARAÇA, 1951), que reflete o movimento das relações fundamentais da unidade de análise.

$\mathrm{O}$ isolado referente ao desenvolvimento do pensamento matemático, em nível teórico, mediado pelo conceito de número, a partir da grandeza ângulo, é composto por quatro episódios. Cada episódio foi definido a partir de indíces de cumprimento das ações correspondentes à tarefa de estudo do conceito de número, a partir da grandeza ângulo, conforme segue: 1) revelação dos dados que compõem a relação essencial do sistema conceitual a partir do estudo com as grandezas; 2) modelação da relação entre os elementos que compõem a essência do sistema conceitual nas formas objetal, gráfica e literal (algébrica); 3) transformação do modelo da relação essencial para o estudo de suas propriedades; 4) construção de um sistema de tarefas particulares que podem ser resolvidas pelo procedimento geral revelado na primeira ação, modelado na segunda e transformado na terceira. Nas duas primeiras ações ocorre o movimento de redução do concreto ao abstrato e nas duas últimas, a ascensão do abstrato ao concreto.

A fonte de dados consiste na transcrição, na íntegra, das manifestações dos(as) acadêmicos(as), da professora titular e do 
professor/pesquisador a partir da gravação do Zoom. A fim de preservar suas identidades, utilizamos a letra A, de acadêmico, seguida de um número para referenciá-los. Quando a fala foi nossa, indicamos PP: Professor Pesquisador ou Professora Pesquisadora.

\subsection{Sistematização do movimento conceitual a ser percorrido}

Ao planejarmos Experimento Didático Desenvolvimental em tempos de pandemia, tínhamos ciência de que seu desenvolvimento ocorreria de forma remota. Além disso, encontramos na grandeza ângulo, ainda nos estudos que sustentam o movimento conceitual, a necessidade da compreensão, por parte dos estudantes, do movimento de rotação que constitui sua gênese.

Essa necessidade nos conduziu em busca de uma ferramenta que possibilitasse aos acadêmicos experenciarem o fenômeno. Nessa busca, deparamo-nos com a ferramenta GeoGebra. Tal ferramenta possibilita a construção de livros dinâmicos que, ante o livro digital, "alteram seu conteúdo a partir da manipulação dos diferentes registros com os quais se relacionam” (NÓBRIGA; SIPLE, 2020, p. 91).

Desse modo, a Situação Desencadeadora de Aprendizagem foi desenvolvida por meio da ferramenta GeoGebra. Ela possibilitou a construção de um livro dinâmico, cuja "característica fundamental consiste na integração de diferentes representações dos objetos da matemática" (NÓBRIGA; SIPLE, 2020, p. 90). O livro dinâmico possibilita a exploração dos objetos da Matemática de forma conectada e simultânea. De acordo com Bellemain (2001 apud NÓBRIGA; SIPLE, 2020, p. 91), "tal princípio permite ao estudante agir direta e livremente sobre a representação do objeto e controlar imediatamente os efeitos dessa ação”.

Nesta perspectiva, integramos a tecnologia à possibilidade de autonomia dos estudantes. Por meio do livro dinâmico, organizamos o processo de ensino-aprendizagem: 
Como se os próprios escolares construíssem o conceito, ainda que sob a direção sistemática do professor (embora a natureza desta direção mude gradualmente e cresça, também muda e cresce gradualmente o grau de autonomia exibido pelo escolar) (DAVÍDOV, 1988, p. 176).

A ferramenta GeoGebra se constituiu parte fundamental no processo de desenvolvimento da Situação Desencadeadora de Aprendizagem, parte mister para revelar a essência da grandeza ângulo ao longo do desenvolvimento do Experimento Didático Desenvolvimental. Contudo, faz-se necessária uma ressalva: primamos pelo movimento conceitual que possibilitasse o desenvolvimento do pensamento matemático em nível teórico. Foi a partir dessa premissa que buscamos uma ferramenta que nos desse suporte para o caminho que pretendíamos trilhar. Portanto, o movimento conceitual deve ser a tônica do processo de ensino-aprendizagem, e que faz sentido, quando aliado ao uso das tecnologias que possam potencializar o teor teórico dos conceitos e seus respectivos sistemas conceituais. Em outras palavras, para que as ferramentas tecnológicas possam desempenhar um papel fundamental na educação escolar contemporânea, devem ser alimentadas com rigor teórico, conforme apresentamos na sequência.

\section{Situação Desencadeadora de Aprendizagem: História Virtual do Conceito}

Elaboramos e desenvolvemos, com os/as acadêmicos/as do Curso de Pedagogia, uma Situação Desencadeadora de Aprendizagem do conceito de número por meio do livro dinâmico (BECKER; ROSA, 2020). 5 A essência do conceito de número consiste na relação de divisibilidade e multiplicidade entre grandezas. Assim, na medição de uma grandeza, toma-se parte dessa mesma grandeza como unidade de medida. A unidade de medida pode ser maior, menor ou igual à grandeza a ser medida. Dentre as diversas grandezas, optamos pela grandeza ângulo.

\footnotetext{
${ }_{5}^{5}$ Disponível na íntegra em: https://www.geogebra.org/m/ms5aqvqx
} 
Com base no movimento lógico e histórico apresentado por Fraga (2016), entendemos que ângulo foi desenvolvido historicamente pela humanidade a partir da necessidade de medir o movimento de rotação em torno um ponto fixo, atualmente representado pelo vértice e delimitado por duas semirretas que partem desse mesmo ponto. Uma semirreta indica o início; e a outra, o término do movimento.

A fim de revelar a essência do conceito teórico de número, a partir da grandeza ângulo, elaboramos uma Situação Desencadeadora de Aprendizagem do tipo História Virtual do Conceito, intitulada Um dia na vida de Artur. Ao elaborá-la, consideramos os elementos que caracterizam uma História Virtual do Conceito, na dinâmica do desenvolvimento da atividade orientadora de ensino.

Ao propormos os problemas que formam consubstanciando a situação desencadeadora de aprendizagem por meio do desenvolvimento das quatro ações de estudo, consideramos o movimento lógico-histórico a fim de reconstruir a gênese e o desenvolvimento do conceito número a partir da grandeza ângulo. Historicamente, tal necessidade foi suprida a partir do controle da quantidade do movimento de rotação e, consequentemente, da quantidade do ângulo de inclinação. Tais necessidades só puderam ser supridas historicamente por meio do conceito de número. Foi a partir dessas necessidades que delimitamos os problemas desencadeadores.

Todo o desenvolvimento foi realizado no contexto da atividade coletiva, desde a identificação e delimitação do problema, perpassando o levantamento de hipóteses de solução até a obtenção das respostas aos problemas, ou seja, a síntese coletiva. Esse processo ocorreu durante a revelação dos elementos que constituem a relação essencial (primeira ação de estudo), repetiu-se quando houve a modelação nas formas objetal, gráfica e literal (segunda ação de estudo), aconteceu novamente na transformação do modelo (terceira ação de estudo) e, por fim, durante a aplicação do modelo (quarta ação de estudo). 
O desenvolvimento das quatro ações de estudo com os estudantes possibilitou reconstruir a síntese histórica do conceito de número em seu estágio mais atual, no contexto de um sistema conceitual, conforme o quadro 1 abaixo.

Quadro 1 - Sistema conceitual contemplado

\begin{tabular}{|l|l|}
\hline Necessidade & $\begin{array}{l}\text { Controle da quantidade do movimento de rotação e de medida de ângulo de } \\
\text { inclinação. }\end{array}$ \\
\hline $\begin{array}{l}\text { Significações } \\
\text { geométricas }\end{array}$ & $\begin{array}{l}\text { 1. Linha reta; 2. linha curva; 3. semirretas; 4. ponto. 5. reta numérica; } \\
\text { 6. unidades de medida básica e intermediária; 7. unidade de medida } \\
\text { padronizada; 8. instrumento de medição (transferidor). }\end{array}$ \\
\hline $\begin{array}{l}\text { Significações } \\
\text { aritméticas }\end{array}$ & 1. Multiplicação; 2. divisão; 3. números naturais; 4. frações. \\
\hline $\begin{array}{l}\text { Significações } \\
\text { algébricas }\end{array}$ & 1. Variável; 2. incógnita; 3. equação. \\
\hline $\begin{array}{l}\text { Movimento } \\
\text { conceitual }\end{array}$ & $\begin{array}{l}\text { 1. Do geral para o particular; 2. redução do concreto ao abstrato; } 3 . \\
\text { ascensão do abstrato ao concreto; 4. quatro ações de estudo; } 5 \text {. unidade } \\
\text { do lógico-histórico. }\end{array}$ \\
\hline
\end{tabular}

Fonte: Elaboração nossa (2020).

Desse modo, possibilitamos que os sujeitos em atividade de estudo vivenciassem a atividade criadora humana e, na especificidade da Situação Desencadeadora em Referência, reproduzimos o processo de origem e desenvolvimento do conceito de número concomitante ao conceito de ângulo no contexto de um sistema conceitual.

\section{Desenvolvimento da Situação Desencadeadora de Aprendizagem}

A fim de desenvolver o conceito de número, a partir da grandeza ângulo, elaboramos a Situação Desencadeadora de Aprendizagem Um dia na vida de Artur e a desenvolvemos por meio da ferramenta GeoGebra (BECKER; ROSA, 2020), compartilhada em tela com os estudantes em cinco partes ou momentos distintos, conforme segue: 


\section{Um dia na vida de Artur - Parte 1}

Artur é um menino cego que usa cadeiras de rodas. Aos seis anos de idade entrou no primeiro ano do Ensino Fundamental com seu amigo e vizinho Pedro, a quem confiava a função de guiar sua cadeira de rodas, quando necessário.

Certo dia, ainda no início do ano letivo, Pedro não foi para a escola e Artur ficou esquecido no pátio ao retornar do recreio. Devido a sua cegueira recente, não conseguia localizar-se nos espaços.

Ao sentir-se sozinho no pátio, lembrou que estava usando o smartwatch que ganhara de aniversário no mês anterior. Por meio do comando de voz, acessou o whatsApp e enviou um áudio ao seu grande amigo Pedro que, ao ouvir, ficou preocupado e pensou: Como puderam esquecer Artur no pátio da escola? De que forma posso ajudá-lo, logo hoje que estou sozinho em casa e não posso pedir auxílio aos meus pais?

Pedro questionou se Artur conseguiria seguir até a entrada do corredor que dá acesso às salas de aula. Artur respondeu que não fazia a menor ideia de como seguir naquela direção. Não sabia qual era sua posição em relação à porta, se estava de frente, de costas ou de lado...

Pedro ficou mais apreensivo do que já estava, pois não sabia como fazer para guiá-lo até a porta do corredor de acesso às salas de aula.

E você, no lugar de Pedro, como faria para ajudar Artur a chegar até a porta que dá acesso às salas de aula?

Fonte: Elaboração nossa, 2020.

\section{Episódio 1 - Primeira ação de estudo}

Ao compor a Situação Desencadeadora de Aprendizagem, definimos previamente o caminho a ser seguido no desenvolvimento da tarefa de estudo, a partir da necessidade que constituiu o conceito de ângulo historicamente. Contudo, ao iniciarmos a primeira ação de estudo, como propõe Davídov (1988, p. 174), “com a finalidade de descobrir a relação universal do objeto, que deverá ser refletida no correspondente conceito teórico", deixamos o problema em questão implícito. Todo o processo foi desencadeado a partir de duas necessidades interdependentes: localização de Artur em relação à porta e quantificação da medida do movimento de rotação, conforme a Cena 1.

Cena 1 - Necessidade de localização e quantificação do movimento de rotação

A9: - Poderia estabelecer um ponto de partida, girar para a direita e para a esquerda.

A12: - Depende de onde ele está e para onde vai.

A5: - Mas ele precisa saber o quanto girar.

A13: - Se estiver de costas, aí giraria dois quartos de uma volta.

A25: - Ele não teria que ter um professor acompanhante?

Fonte: Acervo do TedMat (2020).

Durante as análises, os acadêmicos constataram que, primeiro, era necessário saber a posição de Artur em relação à porta do corredor (A12), para 
depois definir o quanto girar (A13).

A partir de então, levantamos algumas hipóteses a fim de revelar os elementos que compõem a relação essencial (volta inteira e partes da volta). Por exemplo: se Artur estivesse de costas para a porta do corredor que dá acesso às salas de aula, qual orientação você daria para ele (Figura 1)?

Figura 1 - Posição de Artur em relação à porta (de costas)

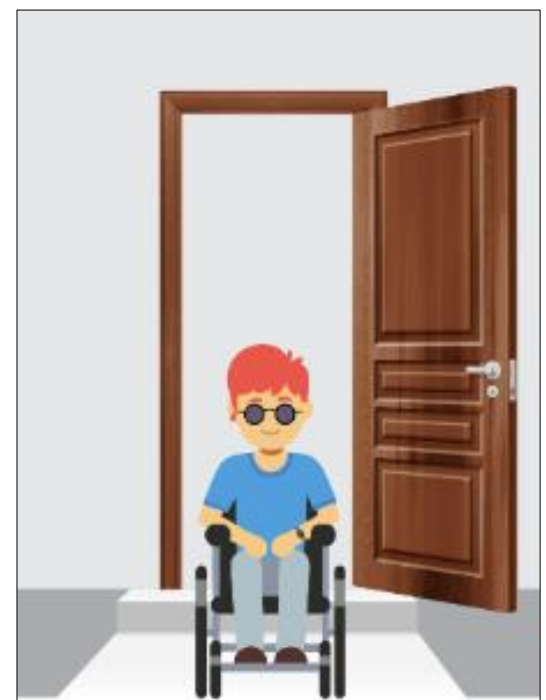

Elaboração: Luana Dagostim Pagani, 2020.

Ao observarem a imagem anterior (Figura 1), compartilhada na tela do computador via livro dinâmico, os acadêmicos afirmaram (Cena 2):

Cena 2 - Revelação dos elementos que compõem a relação essencial

A6: Girar dois quartos da volta.

A8: Ou meia volta, né? [sic]

A6: Isso, um meio.

Fonte: Acervo do TedMat (2020).

As falas supracitadas explicitam a revelação do terceiro elemento que constitui a relação essencial do conceito de número no contexto da grandeza ângulo: quantidade de rotação, tanto no sentido anti-horário quanto horário, sobre um ponto fixo que permitia localizar Artur em direção à porta. Assim, procedemos a partir do entendimento que o movimento de rotação é a gênese do conceito de ângulo. Por meio deste movimento, podemos admitir ângulos superiores a $360^{\circ}$, 
negativos (sentido horário), a possibilidade de representar qualquer número real na circunferência trigonométrica e ainda evitar a compreensão do ângulo como uma grandeza de comprimento (FRAGA, 2016).

Cientes da importância da compreensão do movimento de rotação, de modo análogo, refletimos sobre a possibilidade de Artur estar de lado (tanto virado para esquerda quanto para a direita) e de frente para a porta. Para cada hipótese, questionávamos quantas partes da volta seria necessário rotacionar para posicionar Artur em direção à porta. Assim, também revelamos a essência da grandeza ângulo: localização no contexto do movimento de rotação.

Após revelar a relação essencial do conceito de número em unidade com a relação essencial do conceito de ângulo, iniciamos o processo de representação desses elementos nas formas objetal e gráfica. Primeiro, sugerimos que os acadêmicos experimentassem o movimento de rotação (tanto de uma volta completa como partes dela) com seus próprios corpos e com o corpo de Artur no livro dinâmico (Figura 2).

Figura 2 - Representação dos movimentos de rotação realizados por Artur

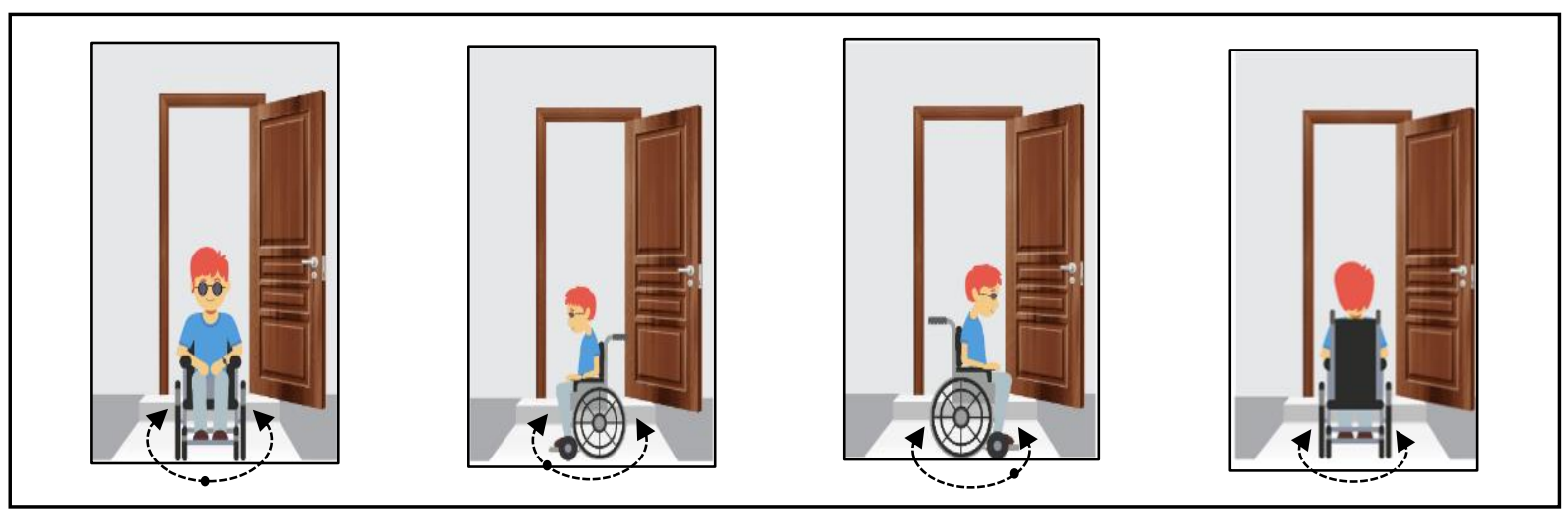

Elaboração: Luana Dagostim Pagani, 2020.

Ao mover o cursor para realizar o movimento de rotação do corpo de Artur, questionávamos: o movimento de Artur representa quantas partes de uma volta? Depois, sugerimos que os acadêmicos representassem o movimento que realizaram com seus corpos por meio de um leque decorativo, elaborado previamente pelos acadêmicos (Figura 3). 
Figura 3 - Representação objetal da medida do movimento de rotação
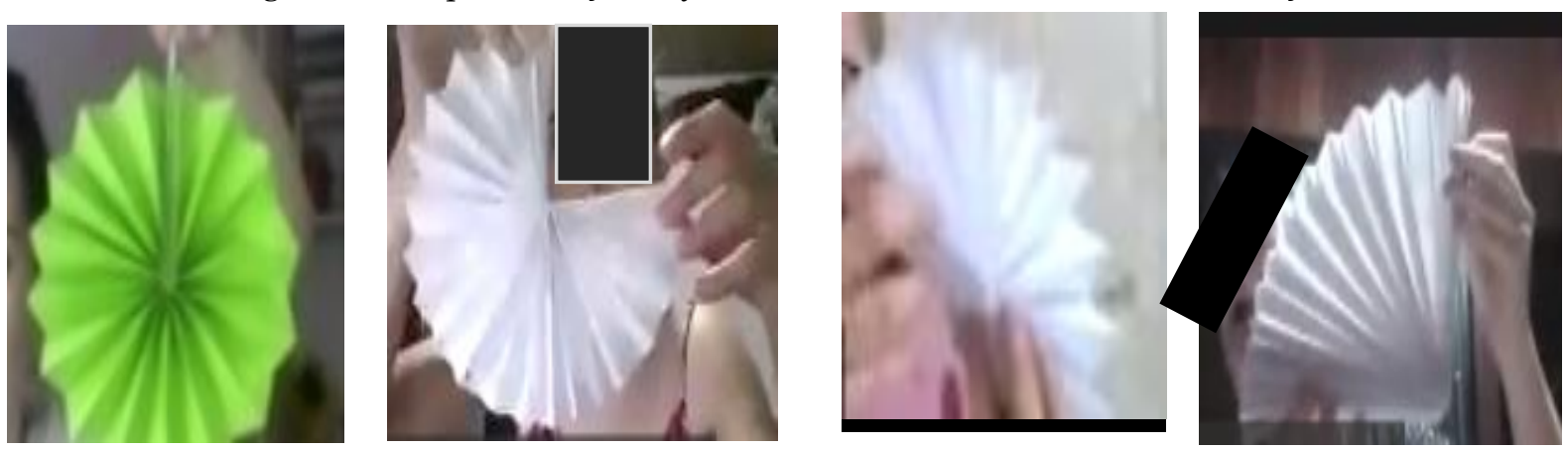

Fonte: Acervo do TedMat (2020).

Optamos pelo leque decorativo em função da possibilidade de representarmos, por meio desse objeto, a essência do conceito de ângulo: início e fim do movimento de rotação em torno de um ponto. Em sincronia com a representação do movimento de rotação no plano objetal, também representávamos graficamente no GeoGebra, por meio de um ponto fixo e duas semirretas (ou dois vetores), uma fixa para indicar o início do movimento e outra móvel para representar o movimento realizado, desde o início até seu término (Figura 4):

Figura 4 - Representação gráfica da quantidade do movimento de rotação

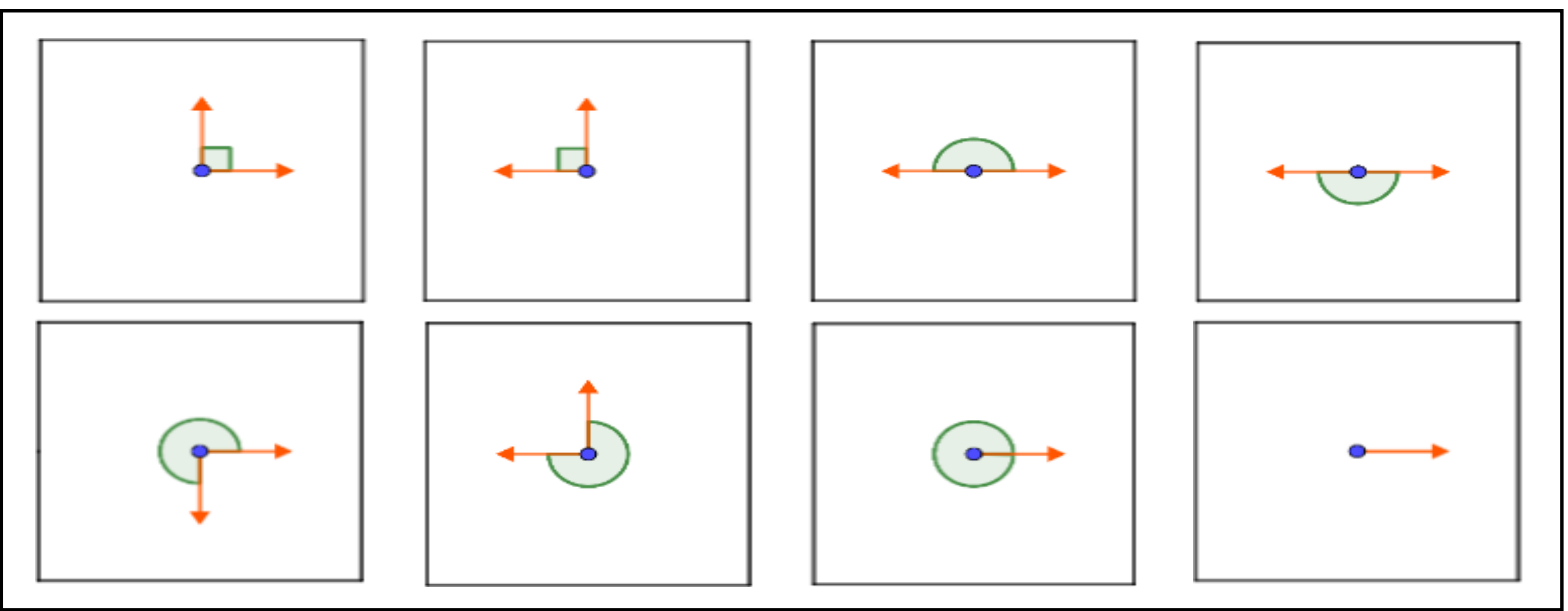

Fonte: Elaboração nossa (2020).

A sincronia entre a representação objetal e a gráfica contribuiu para que os estudantes abstraíssem os elementos do ângulo, a partir de sua gênese, por meio de elementos geométricos, como ponto (vértice) e semirretas (vetores). 
Para Davídov (1988, p. 145), “a base desse processo é a relação objetal absolutamente real, sensório-perceptível, a 'célula' dessa concretude”. A relação objetal é parte fundamental do Experimento Desenvolvimental no início do desenvolvimento das três primeiras ações de estudo. Contudo, é preciso enfatizar que objetos utilizados devem possibilitar a revelação da essência do conceito em estudo.

Após nos certificarmos que a turma havia compreendido a relação de dependência da medida do movimento de rotação em função da localização (ponto inicial e final), caminhamos para a resolução do problema desencadeador por meio do acréscimo de mais um trecho da História Virtual do Conceito.

\section{Um dia na vida de Artur - Parte 2}

Enquanto Pedro levantava as diversas possibilidades de posição de Artur, a porta de acesso ao corredor das salas bateu forte, e Artur percebeu que estava de costas para ela. Porém, ambos estavam tão apreensivos que não conseguiram identificar qual movimento deveria ser realizado com a cadeira de rodas.

Qual sua orientação para que Artur se posicione em direção à porta?

Fonte: Elaboração nossa (2020).

Dada nossa intencionalidade com a segunda parte da Situação Desencadeadora de Aprendizagem, questionamos: agora que já sabemos a posição real de Artur, qual orientação vocês dariam para que ele possa chegar até a porta que dá acesso às salas de aula?

Cena 3 - Resposta ao primeiro problema desencadeador

A19: - Duas partes.

A13: - Dois quartos de volta.

A26: - Isso.

PP: - Faria alguma diferença se fosse pra esquerda ou pra direita? [sic]

A13: - Não.

A5: - De costas, não; se estivesse de lado, sim.

A4: - Se ele for para a esquerda ou pra direita, vai ficar de frente para [a] porta. [sic]

Fonte: Acervo do TedMat (2020).

Com a resposta ao primeiro problema desencadeador, concluímos a primeira ação de estudo. 


\section{Episódio 2 - Segunda ação de estudo}

Ao constatarmos que a orientação correta para Artur seguir em direção à porta do corredor que dá acesso às salas era uma proposição coletiva, demos início às reflexões sobre um novo obstáculo que Artur encontrou no caminho.

\section{Um dia na vida de Artur - Parte 3}

Pedro solicitou ao amigo que girasse meia volta para a esquerda. Assim, Artur conseguiu seguir em direção à porta do corredor que dá acesso às salas de aula. Contudo, ao se aproximar da porta, bateu em um degrau e não conseguiu subir sozinho.

Ao gritar pedindo ajuda, teve auxílio de uma merendeira que estava guardando as panelas na despensa. A merendeira seguiu com Artur até sua sala e contou para a turma o que havia acontecido. Todos ficaram pensativos: - como pudemos ter esquecido Artur no pátio?

Ao relatar a experiência para a turma, Artur foi categórico: - A pior parte foi não conseguir subir sozinho o degrau que dá acesso ao corredor das salas!

A professora Margarida questionou a turma: - Já que todos somos responsáveis pelo que aconteceu com Artur, o que podemos fazer para solucionar esse problema de uma vez por todas? A turma não encontrou uma solução e combinou que pediriam ajuda para o professor Francisco, do quinto ano do Ensino Fundamental. Foram até sua sala e relataram o ocorrido. Seus estudantes, ao ouvirem o que acontecera com Artur, compadeceram-se e quiseram participar da solução do problema.

Depois de muito debaterem, concluíram que a solução seria a construção de uma rampa. Para agilizar o processo, decidiram eles mesmos elaborar o projeto e propor sua construção para a diretora da escola. Mas se depararam com um problema: como deverá ser a rampa para que Artur consiga subir e descer de forma autônoma, sem precisar que alguém empurre sua cadeira de rodas?

Fonte: Elaboração nossa (2020).

Durante as reflexões sobre o terceiro problema desencadeador, sugerimos que os acadêmicos construíssem rampas, com recortes de papel, com a medida do ângulo de inclinação que consideravam adequada. Após todos concluírem, fizemos questionamentos, conforme a Cena 4.

\section{Cena 4 - Reflexões sobre inclinação}

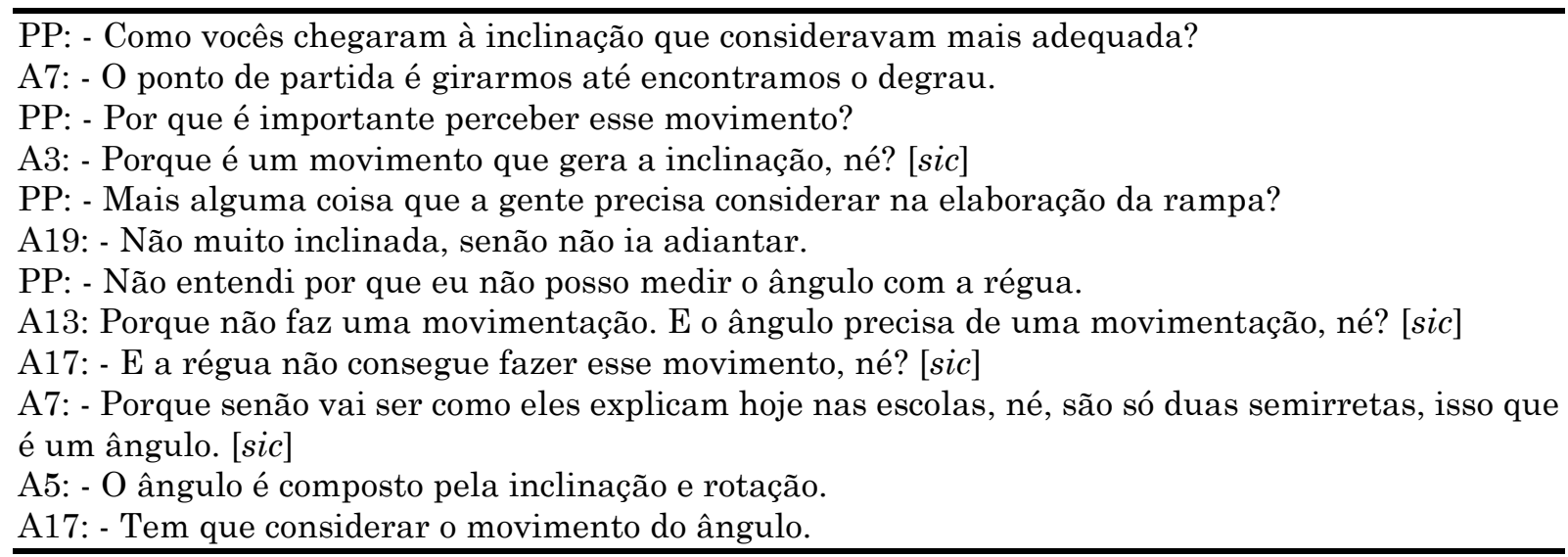

Fonte: Acervo do TedMat (2020). 
As falas dos estudantes evidenciam que a essência revelada na primeira ação de estudo foi considerada durante o processo de elaboração da rampa, uma operação prático-sensorial aparentemente diferente do movimento de rotação realizado com a cadeira de rodas. Isto porque, conforme afirma Kopnin (1978, p. 52), o reflexo do mundo objetivo "na consciência do homem não é algum estado ancilosado, não é uma cópia morta da realidade, mas um processo de aprofundamento na essência das coisas".

Em outras palavras, a essência revelada na primeira ação foi concretizada, em termos práticos, durante a construção da rampa, o que possibilita o processo de sua modelação, a partir da apresentação de uma nova necessidade e um novo problema desencadeador.

\section{Um dia na vida de Artur - Parte 4}

Os estudantes, com orientação do professor Francisco, fizeram uma rampa, com recortes de papel, com o ângulo de inclinação que consideravam adequada para Artur subir e descer de forma autônoma. Então, era só passar o projeto para a diretora e solicitar sua construção.

Ao observar a euforia da turma do professor Francisco, Artur se manteve em silêncio e, preocupado, questionou: como o pessoal que vai construir a rampa saberá qual deverá ser a medida adequada do ângulo de inclinação?

Nesse momento, a euforia se esvaiu. Deram-se conta que não incluíram essa informação no projeto, e se viram diante de um problema por eles desconhecido: como fazer para medir o ângulo de inclinação da rampa?

Como podemos explicar para Artur e seus colegas qual procedimento possibilita a medição do ângulo de inclinação da rampa?

Fonte: Elaboração nossa (2020).

Questionamos se seria possível medir o ângulo de inclinação da rampa a partir das subdivisões da volta que havíamos realizado durante as reflexões sobre quantos quartos de volta Artur deveria rotacionar. A turma não compreendeu a pergunta e foi necessário apresentar algumas perguntas para auxiliar (Cena 5).

Cena 5 - Relação de multiplicidade e divisibilidade

PP: - Até agora, então, o que nós fizemos com a volta?

A7: Nós dividimos ela em 4 partes. [sic]

PP: - Quais operações matemáticas permitiram vocês chegarem a essa conclusão?

A3: - No caso, seria a divisão quando dividir as partes, e multiplicação quando for multiplicando o tanto de vezes que girou.

PP: - Quais são as duas operações que dão origem tanto ao número natural quanto à fração? A22: - Multiplicidade e divisibilidade.

Fonte: Acervo do TedMat (2020). 
A partir da Cena 5, surgiu a seguinte reflexão: por que a grandeza ângulo não é considerada durante a introdução dos números naturais e racionais? Por que primeiro se aprendem os números para depois aprender ângulo? Por que fragmentamos, no ensino, algo que é inseparável do ponto de vista da Matemática? A conclusão a que chegamos é que tal fragmentação ocorre por falta de compreensão dos conceitos matemáticos no contexto de seus sistemas conceituais, a partir da relação essencial que os unifica na interconexão das significações aritméticas, algébricas e geométricas. Nesse sentido, questionamos: como podemos representar as subdivisões da volta completa geometricamente?

Cena 6 - Consequências da relação de multiplicidade e divisibilidade

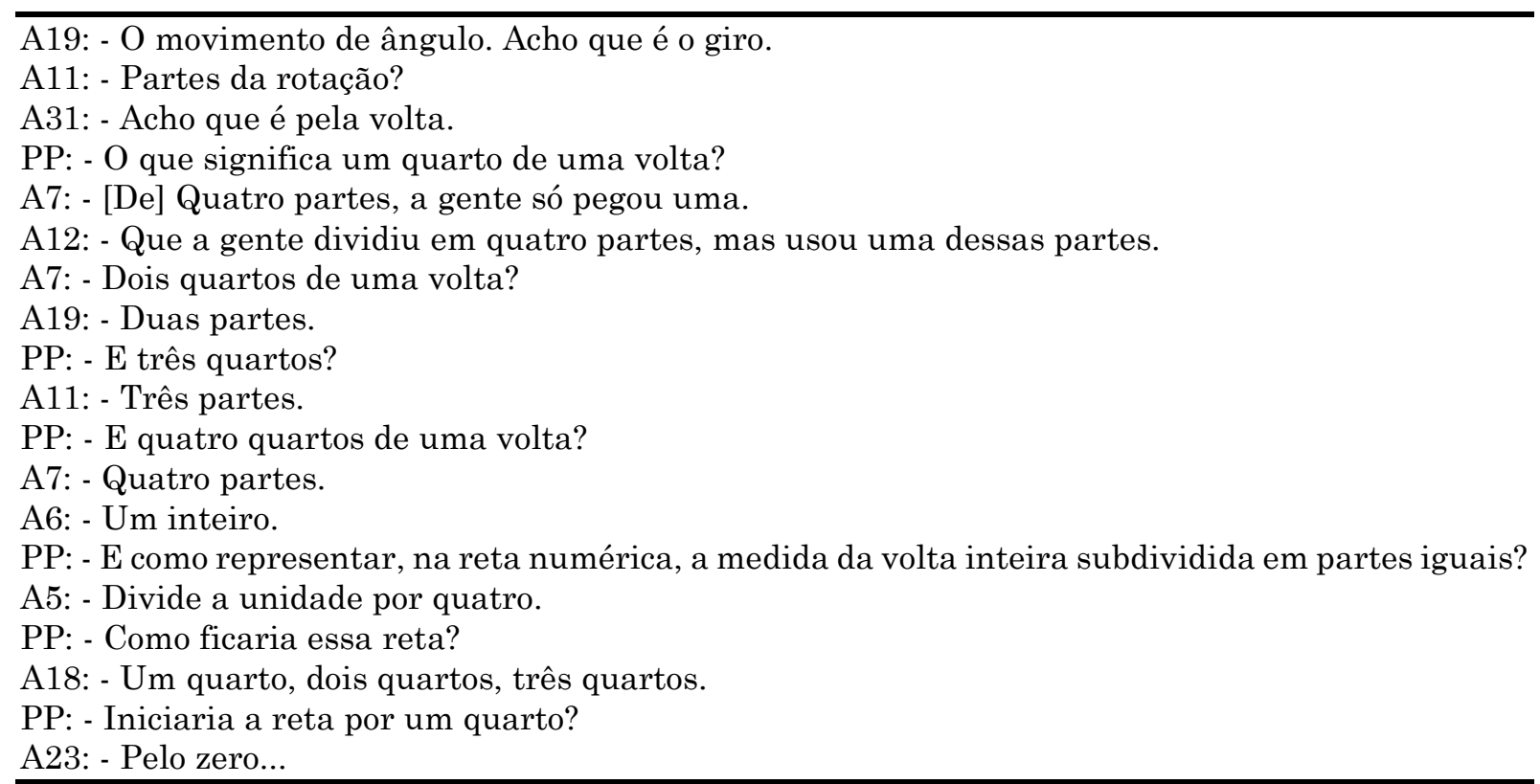

Fonte: Acervo do TedMat (2020).

Durante o diálogo anterior (Cena 6), procedemos à modelação gráfica por meio de elementos geométricos. Conforme os acadêmicos respondiam corretamente, introduzíamos as seguintes imagens no livro dinâmico compartilhado na tela (Figura 5). 
Figura 5 - Revelação da conexão interna dos elementos que compõem a relação essencial

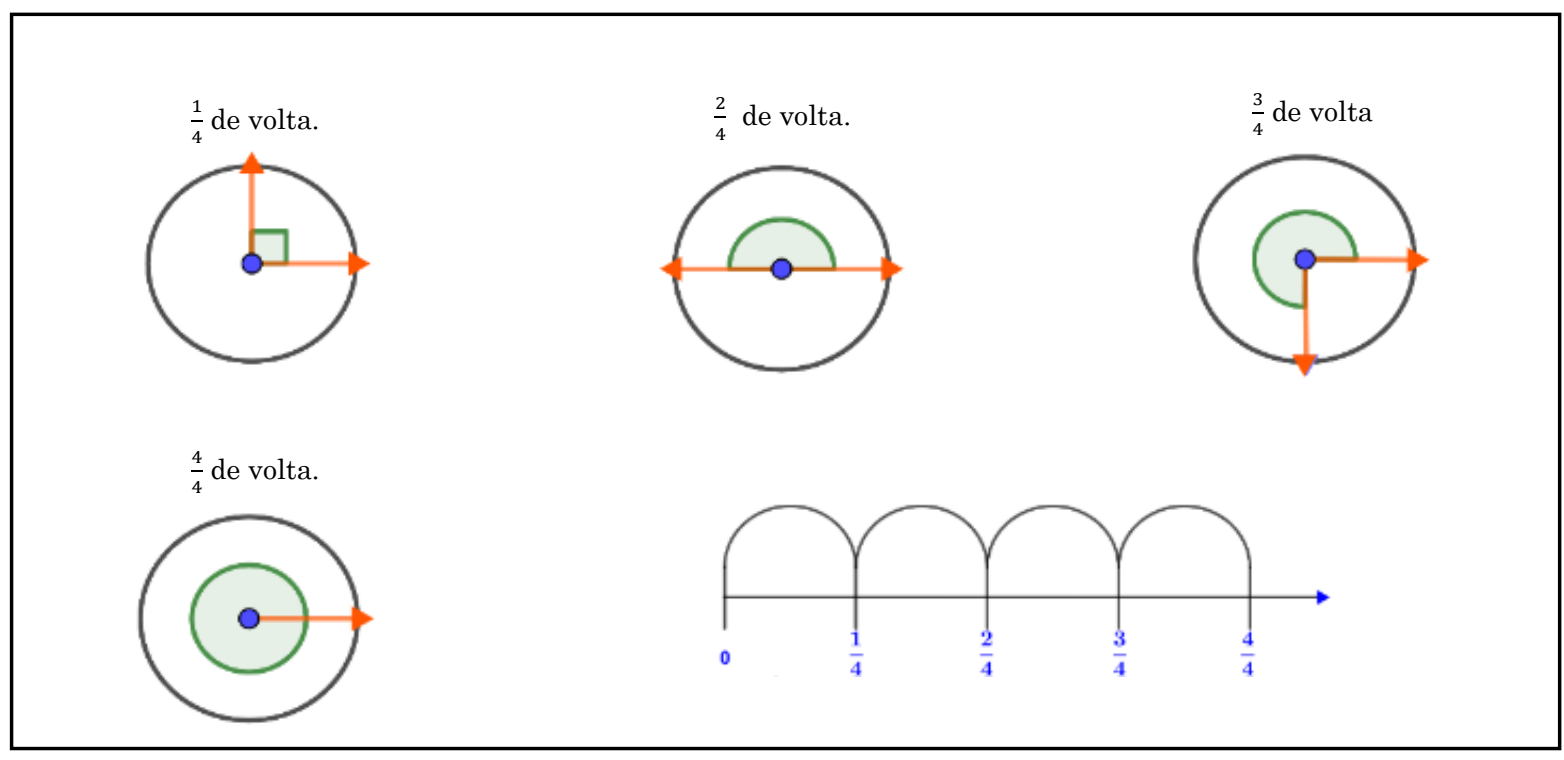

Fonte: Elaboração nossa (2020).

Quando chegamos aos quatro quartos na reta numérica, questionamos se poderíamos continuar ou teríamos que parar naquele ponto (Cena 7).

Cena 7 - Para além de uma volta

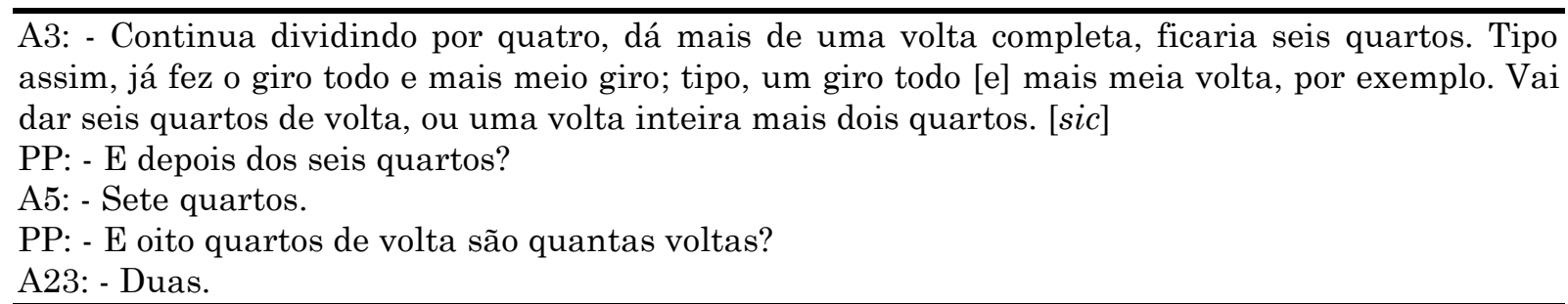
Fonte: Acervo do TedMat (2020).

A partir de tais respostas, concluímos que a relação de multiplicidade e divisibilidade entre a volta completa e suas partes foi generalizada para além da situação particular do movimento de rotação da cadeira de rodas de Artur. Tal constatação nos indicou a possibilidade de avançar no movimento de abstração substancial, abstração da essência, que está no cerne do desenvolvimento do pensamento teórico (DAVÍDOV, 1988), por meio da introdução das significações algébricas. Questionamos se poderíamos tomar um quarto de volta como unidade de medida da volta (Cena 8): 
Cena 8 - Introdução da unidade de medida

A5: - Sim.

PP: - E como ficaria?

A17: - Acho que só ali aonde está representada quatro quartos, cinco quartos... a gente coloca letras. [sic]

PP: - Se representássemos a unidade de medida com a letra E, como ficaria?

A19: - 1E, 2E, 3E e 4E.

PP: - Como representamos nenhuma unidade E na reta numérica?

A30: - Zero.

Fonte: Acervo do TedMat (2020).

Anteriormente (Cena 7), subdividimos a volta em quatro partes iguais. Obtivemos como resultado $\frac{1}{4}$. Na Cena 8 , tomamos um quarto como unidade de medida intermediária e o representamos pela letra E. Conforme o diálogo ocorria, introduzíamos as seguintes imagens no livro dinâmico (Figura 6).

Figura 6 - Modelação gráfica

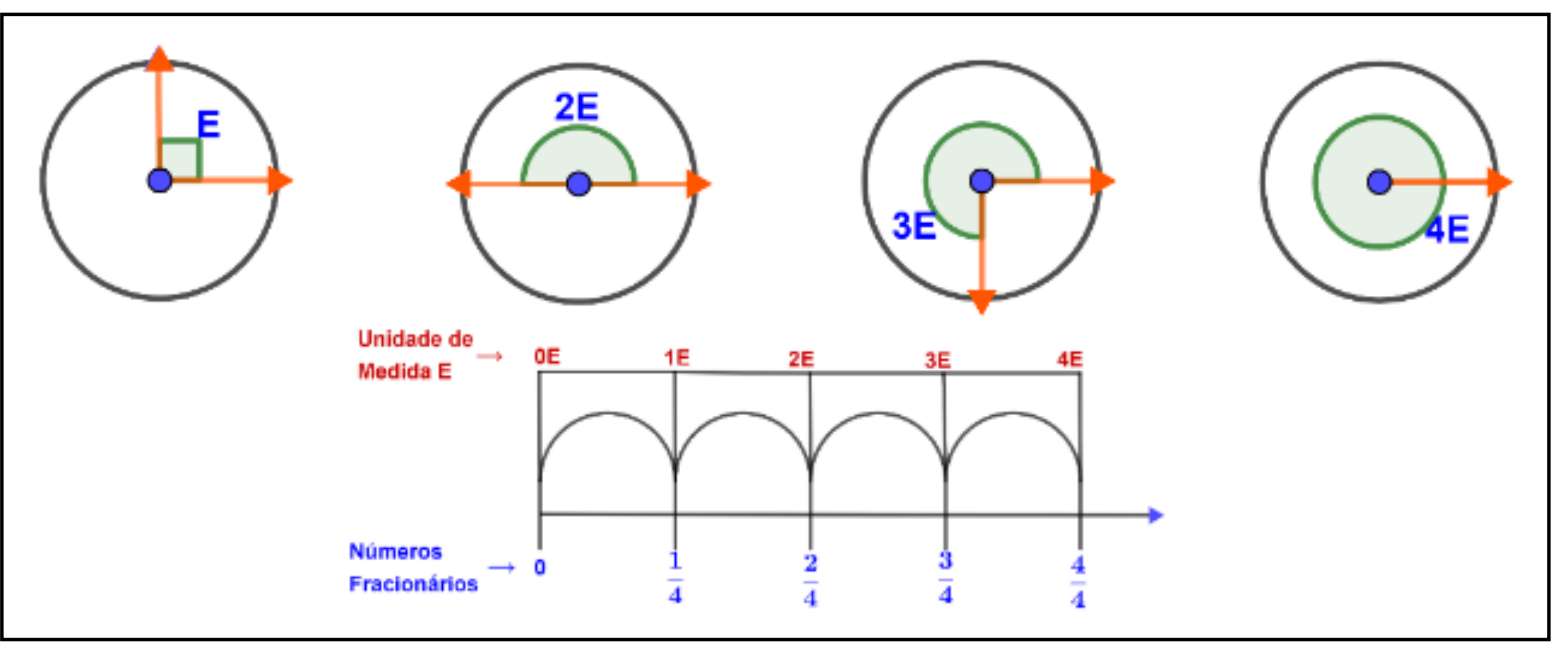

Fonte: Elaboração nossa (2020).

Nesse momento estavam expostas na tela, via livro dinâmico, as significações geométricas, aritméticas e algébricas de modo interconectado (Figura 6). Tal interconexão ocorre a partir da célula que dá origem a todos os números no campo dos reais. Com o intuito de explicitar tal célula e avançarmos no movimento de abstração, fizemos novos questionamentos (Cena 9). 
Cena 9 - Revelação da célula

PP: - 4E é igual ao quê?

A3: - À volta.

A19: - Uma volta completa.

A3: - Quais modelos representam a relação entre a unidade de medida E e a volta inteira?

A12: - 4E é igual uma volta inteira.

PP: - Podemos atribuir uma letra para uma volta inteira?

A12: - Sim.

A5: - Pode ser 4E igual a V.

PP: - Podemos formar outros modelos?

A11: - V dividido por 4 é igual a $\mathrm{E}$.

A3: - $\mathrm{V}$ dividido por E é igual a 4.

Fonte: Acervo do TedMat (2020).

As respostas dos acadêmicos, a partir da relação entre a volta completa (V) e a unidade de medida E, consiste nos modelos ilustrados na Figura 7.

Figura 7 - Modelação literal

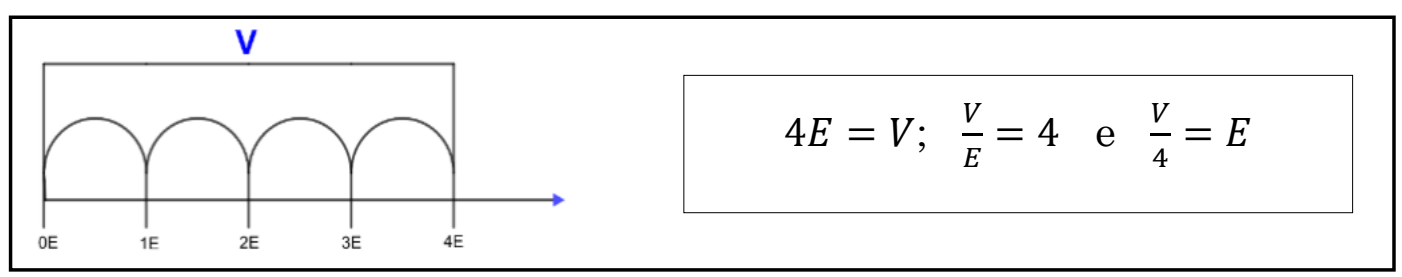

Fonte: Elaboração nossa (2020).

$\mathrm{Na}$ imagem anterior (Figura 7 ), temos a representação da relação de divisibilidade $\left(\frac{V}{E}=4\right.$ e $\left.\frac{V}{4}=E\right)$ e multiplicidade $(4 E=V)$ entre a volta e a unidade de medida E. Mas se a volta completa, ao invés de ser subdividida em quatro partes iguais, fosse subdividida em três partes, permaneceria a mesma unidade de medida E? E se fosse subdividida em duas partes? A conclusão foi que teríamos novas unidades de medida. Combinamos que as novas unidades de medidas seriam representas pelas letras $\mathrm{H}$ e $\mathrm{F}$, respectivamente, conforme a figura 8. 
Figura 8 - Outros modelos particulares a partir de novas unidades de medidas
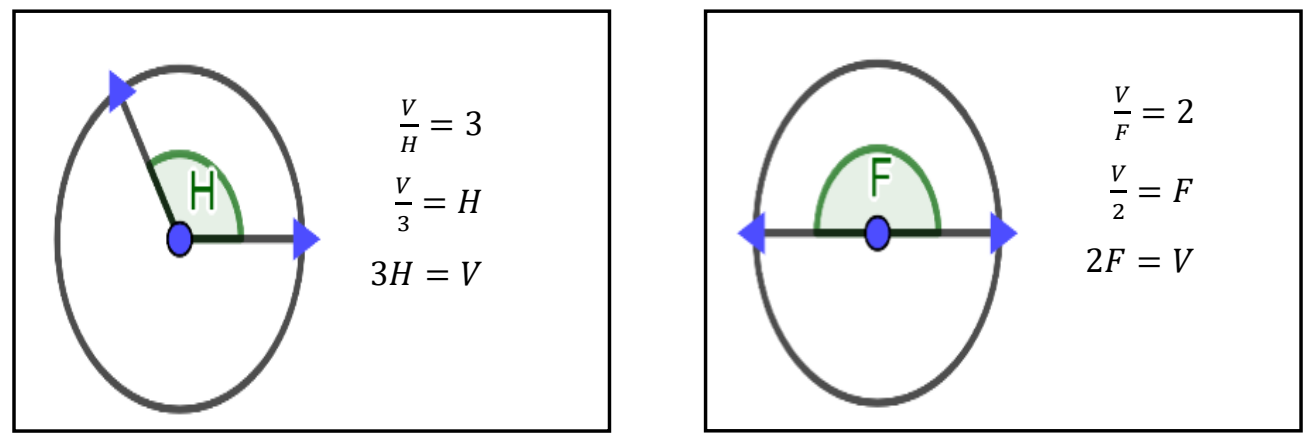

Fonte: Elaboração nossa (2020).

As modelações anteriores são de caráter particular. A primeira é válida para os casos em que a volta foi subdividida em quatro partes iguais (Figura 6); depois três; e, por fim, duas. Mas se considerarmos um modelo geral, por exemplo: $\frac{V}{P}=n$. Para P igual a E, qual será o valor de $n$ ? Os acadêmicos responderam $n=4$ com tranquilidade. De modo análogo, procedemos com as unidades H e F.

O modelo $\frac{V}{P}=n$ consiste na representação da relação essencial na sua forma geral e, portanto, válida para qualquer situação particular, onde V representa a volta; $\mathrm{P}$, a unidade de medida obtida a partir de subdivisões da volta; e $n$, a quantidade de vezes que a unidade de medida se repete.

Ao realizarmos a modelação na forma geral, atingimos a abstração máxima, assim, concluímos o procedimento de redução do concreto ao abstrato e findamos a segunda ação de estudo. Na sequência, iniciamos o procedimento de ascensão do abstrato ao concreto durante o desenvolvimento da terceira ação de estudo.

\section{Episódio 3 - Terceira ação de estudo}

Durante a segunda ação de estudo, revelamos três unidades de medida (E, H e F). Por meio dessas unidades, é possível medir o ângulo de inclinação da rampa? Suponhamos que a rampa projetada pelos estudantes da turma do professor Francisco tenha as dimensões dispostas na Figura 9. Seu ângulo de inclinação é possível com a unidade de medida F? 
Figura 9 - Medição do ângulo de inclinação com a unidade de medida $\mathrm{F}$

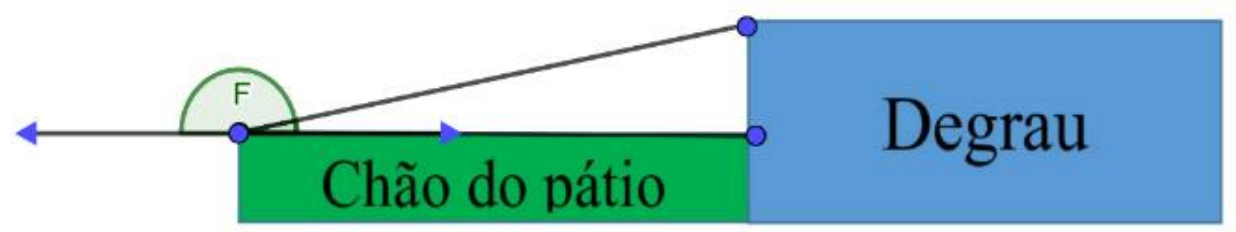

Fonte: Elaboração nossa (2020).

A partir da observação da imagem anterior (Figura 9) na tela compartilhada, seguiu-se o diálogo da Cena 10.

Cena 10 - Revelação da necessidade de subdivisão da unidade de medida

PP: - É possível medir o ângulo de inclinação da rampa com a unidade de medida F?

A13: - Temos que dividi-la.

PP: - O ângulo de inclinação da rampa é maior ou menor que F?

A12: - Menor.

PP: - Menor que um F inteiro?

A10: - Sim.

Fonte: Acervo do TedMat (2020).

E se a unidade de medida utilizada for menor que F (Figura 10)?

Figura 10 - Medição do ângulo de inclinação com as unidades de medida H e E
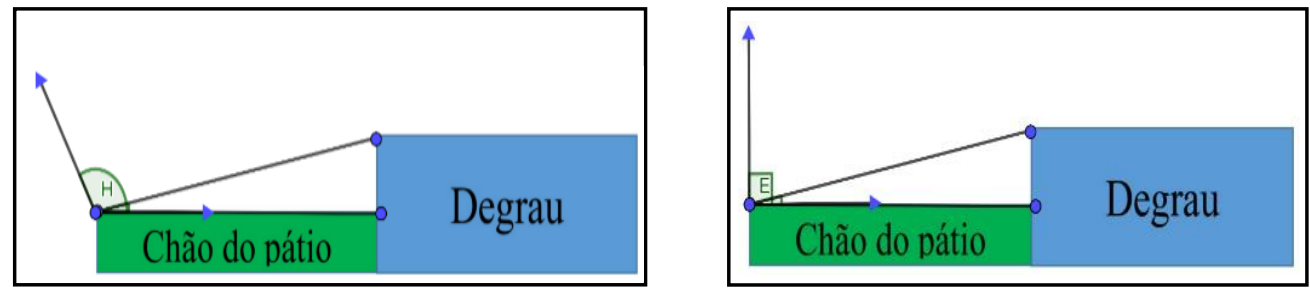

Fonte: Elaboração nossa (2020).

A partir da análise das medições com as unidades de medidas $\mathrm{H}$ e E, ocorreu o diálogo disposto na Cena 11.

Cena 11 - Generalização do procedimento

A12: - Tem que fracionar.

A17: - Criar uma nova unidade de medida.

PP: - Como faremos isso?

A6: - Dividindo a volta toda em partes iguais.

Fonte: Acervo do TedMat (2020). 
A resposta de A6 indica apropriação do procedimento geral para determinação de novas unidades de medida. Assim como os estudantes da turma em referência, a humanidade também vivenciou, historicamente, a necessidade de unidades de medidas cada vez menores para realizar medições cada vez mais precisas. Isso ocorre porque, no contexto do desenvolvimento de uma Situação Desencadeadora de Aprendizagem do tipo História Virtual do Conceito, a necessidade humana que gera e desenvolve o conceito está encarnada no movimento lógico-histórico percorrido ao longo de sua solução.

A partir da necessidade vivenciada historicamente de subdivisão da unidade, os estudantes apresentaram, como possibilidade de solução, subdividir a volta em um número maior de partes iguais. Sugerimos, então, subdividi-la em 36 partes e fizemos os questionamentos dispostos na Cena 12.

Cena 12 - Subdivisão da volta a partir do modelo geral

PP: - Como representamos o modelo universal escrito na forma geral?

A30: $-\frac{V}{P}=n$.

PP: - E para P igual a 36, qual será o valor de $n$ ?

A12: -V divido por 36.

PP: - Igual a quanto?

A11: - Igual a $n$.

PP: - E qual é o valor de $n$ ?

A12: - Um trinta e seis avos.

PP: - Pessoal, se nós dividimos a volta completa em 36 partes iguais, nós vamos ter uma nova unidade de medida?

A3: - Sim.

PP: - Podemos colocar qualquer letra para representar a nova unidade de medida?

A11: - Sim, menos as que já foram utilizadas.

Fonte: Acervo do TedMat (2020).

Combinamos que a nova unidade de medida seria representada pela letra $\mathrm{T}$ $\left(\mathrm{T}=\frac{1}{36}\right)$, conforme a figura 11 a seguir.

Figura 11 - Subdivisão da volta em 36 partes iguais

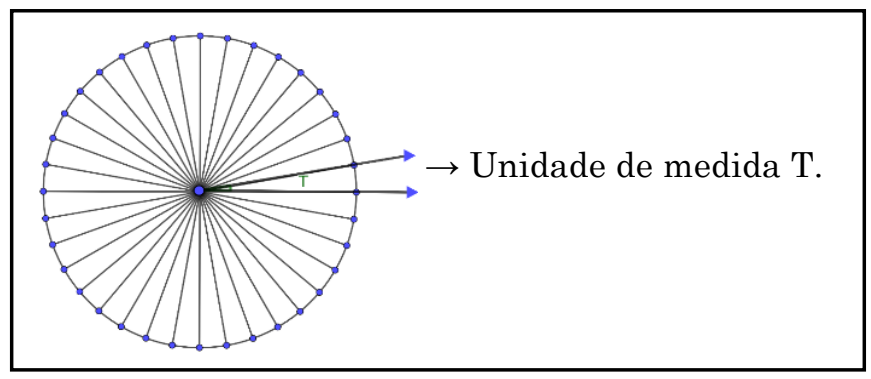

Fonte: Elaboração nossa (2020). 
Ao dividirmos a volta em 36 partes iguais, resolvemos o problema da medição do ângulo de inclinação da rampa? É possível medir o ângulo de inclinação da rampa com a unidade de medida T (Figura 11)? Após os estudantes responderem positivamente, procedemos à medição (Figura 12).

Figura 12 - Medição do ângulo de inclinação com a unidade de medida T

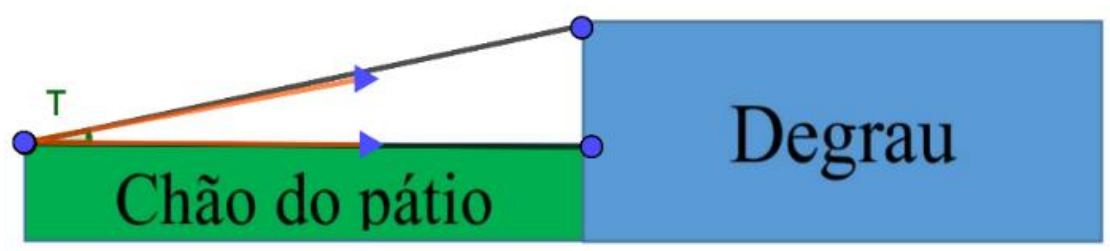

Fonte: Elaboração nossa (2020).

A unidade de medida T, assim como as anteriores, foi apresentada enquanto movimento. Assim, as duas semirretas estavam sobrepostas no ponto de partida (chão) e, a partir do movimento de rotação, uma das semirretas deslocou-se até atingir o ângulo de medida T. Após esse movimento ocorreu o diálogo da Cena 13.

Cena 13 - Subdivisão da volta em 360 partes

PP: - Conseguimos medir?

A3: - Sim.

A11: - Não, ainda não está bem certinho no nível. Para mim, pelo menos, não parece certinho.

A19: - O laranja está um pouquinho abaixo.

PP: - De que forma podemos proceder para seja possível medir o ângulo de inclinação da rampa?

A11: - Dividir por 360.

A10: - E medir de grau em grau então.

PP: - Considerando o modelo geral $\frac{V}{P}=n$. Para P igual a 360, qual será o valor de $n$ ?

A12: $-\frac{\mathrm{V}}{360}=\frac{1}{360}$.

A7: - Uma parte dessa é o grau.

Fonte: Acervo do TedMat (2020).

Após a fala de A7, combinamos que a nova unidade de medida seria representada pela letra $\mathrm{G}$. Os diferentes resultados do processo de medição decorrem da variação da unidade de medida. Tais transformações possibilitaram o estudo das propriedades da relação da grandeza a ser medida com a unidade de medida em sua forma pura (em sua forma abstrata) a partir do modelo. Quanto menor a unidade de medida, maior será o número concreto que representa a relação da grandeza em medição com a unidade de medida. Por outro lado, quanto maior 
a unidade de medida, menor será o número que representa a relação da grandeza em medição com a unidade de medida.

Algumas propriedades gerais do conceito de número são estudadas mesmo antes da diversidade de suas manifestações particulares. De acordo com Davídov (1988, p. 215), isso ocorre porque a passagem do geral para o particular também se realiza pela substituição dos "símbolos expressos por letras pelos símbolos numéricos concretos. É importante destacar que este trânsito se realiza como estruturação autêntica do concreto a partir do abstrato [...]”. O procedimento de concretização teve continuidade na quarta ação de estudo.

\section{Episódio 4 - Quarta ação de estudo}

E agora, já temos condições de resolver o problema de medição do ângulo de inclinação da rampa? O que os estudantes do quinto ano precisam fazer para medilo? Em outras palavras, qual a medida do AÔB (Figura 13)?

Figura 13 - Medição do ângulo de inclinação da rampa por meio da unidade de medida grau

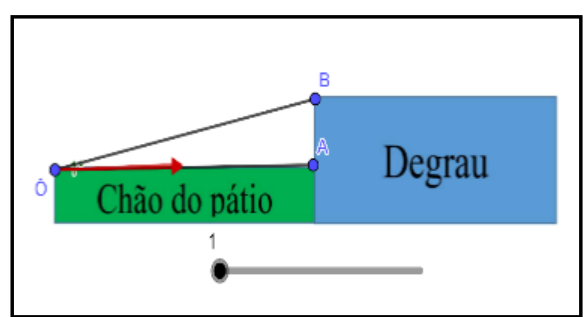

A

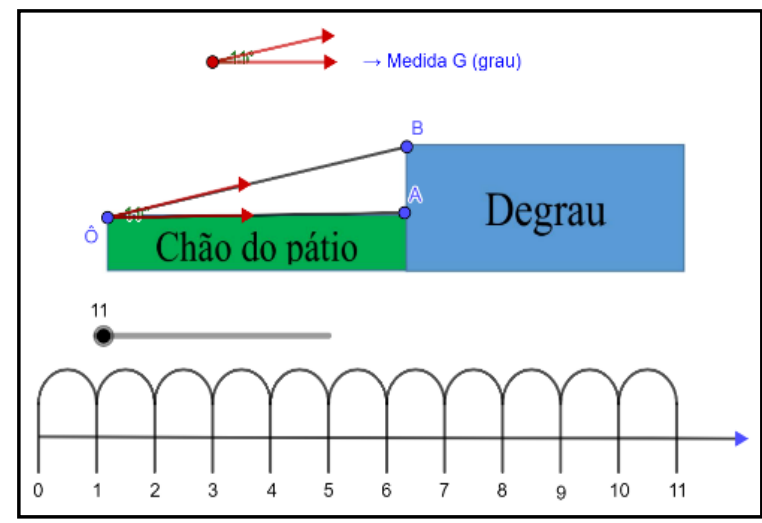

B

Fonte: Elaboração nossa (2020).

Incialmente, realizamos o procedimento de medição no GeoGebra, de grau em grau (Figura 13a), até atingir a totalidade do ângulo de inclinação da rampa (Figura 13b). Depois, realizamos a medição com o transferidor, instrumento padronizado para tal fim (Figura 14). 
Figura 14 - Representação da medição da rampa por meio do transferidor

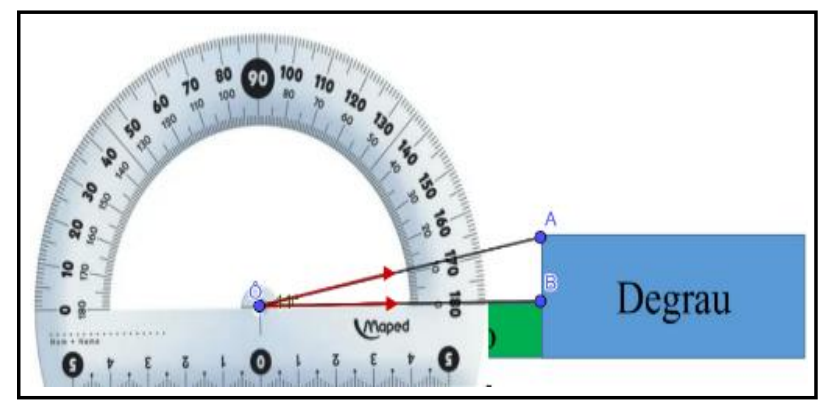

Fonte: Elaboração nossa (2020).

Após a medição, encaminhamos o diálogo descrito na Cena 14.

Cena 14 - Resultado da medição

PP: - Quanto mede a inclinação da rampa?

A11: - 11 graus $\left(11^{\circ}\right)$.

PP: - O que gera a inclinação?

A30: - O movimento de rotação.

A6: - A gente está aprendendo um conceito geral que a gente pode aplicar em diversas situações.

Fonte: Acervo do TedMat (2020).

No transferidor (Figura 14), está objetivado o procedimento geral de medição do ângulo revelado na primeira ação, modelado na segunda e transformado na terceira. $\mathrm{O}$ desenvolvimento das quatro ações de estudo reflete o movimento lógico-histórico da atividade criadora humana do conceito de ângulo em unidade dialética com o conceito de número. A experiência da atividade criadora é "o elemento principal e fundamental, que apoia os outros elementos (conhecimento, capacidades e relações do indivíduo com o mundo) para que se desenvolvam" (DAVÍDOV, 1988, p. 162).

Nessa última ação, concretizamos o procedimento geral de medição de ângulo e, consequentemente, o procedimento geral que dá origem aos infinitos números reais. Ao concluí-la, revelamos a característica numérica do ângulo de inclinação da rampa.

Também consideramos importante refletir, com a turma, a relação entre as medidas G, E e V. A partir das reflexões, atingimos a seguinte síntese: G (grau) é a unidade de medida básica; E, a unidade de medida intermediária; e V, a volta completa. Portanto: $1 \mathrm{E}=90^{\circ} ; 2 \mathrm{E}=180^{\circ} ; 3 \mathrm{E}=270^{\circ}$ e $4 \mathrm{E}=360^{\circ}$, conforme a figura 15 . 
Figura 15 - Representação concreta da relação entre as medidas G, E e V

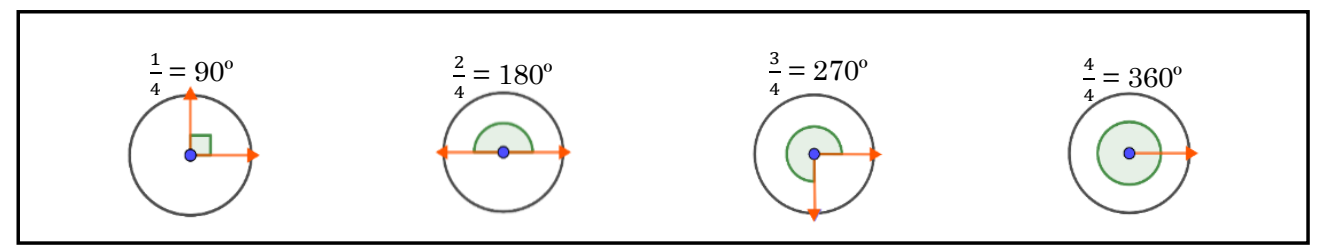

Fonte: Elaboração nossa (2020).

A mesma reflexão foi realizada com as demais unidades (F, H e T). Desse modo, concluímos o movimento conceitual orientado do geral para particular, tal como propõe Davídov (1988, 1982):

A partir da relação geral, os escolares constroem a generalização substantiva, que permite deduzir relações mais particulares do conceito e, portanto, concretizá-lo (DAVÍDOV, 1988). Para finalizar o desenvolvimento da História Virtual do Conceito - Um dia na vida de Artur - com os acadêmicos, partimos da necessidade de comunicar a síntese teórica do conhecimento desenvolvido nas quatro ações de estudo.

\section{Um dia na vida de Artur - Parte 5}

Artur está muito feliz, pois aprendeu com essa experiência como se faz para medir o movimento de rotação e a medida do ângulo de inclinação. Ele também constatou o quão importante seria se todos soubessem como proceder em qualquer situação que envolvesse a necessidade desse conhecimento. Por essa razão, decidiu publicar sua explicação.

Imagine que você é escriba de Artur e que ele pediu para você registrar como se mede o movimento de rotação e a medida do ângulo de inclinação em qualquer situação. Na condição de escriba de Artur, como você faria esse registro?

Fonte: Elaboração nossa (2020).

Os acadêmicos responderam ao problema desencadeador da parte 5 individualmente, porém não apresentaremos no presente artigo por falta de espaço. Subjacente às produções dos acadêmicos, ao término do desenvolvimento da Situação Desencadeadora de Aprendizagem, houve indícios de uma atitude teórica.

Os cinco problemas desencadeadores desenvolvidos anteriormente tinham em comum a mesma essência. Em torno dela, ocorreu o movimento de busca de solução no contexto das quatro ações de estudo, conforme segue (Figura 16): 
Figura 16 - Síntese do movimento do pensamento teórico

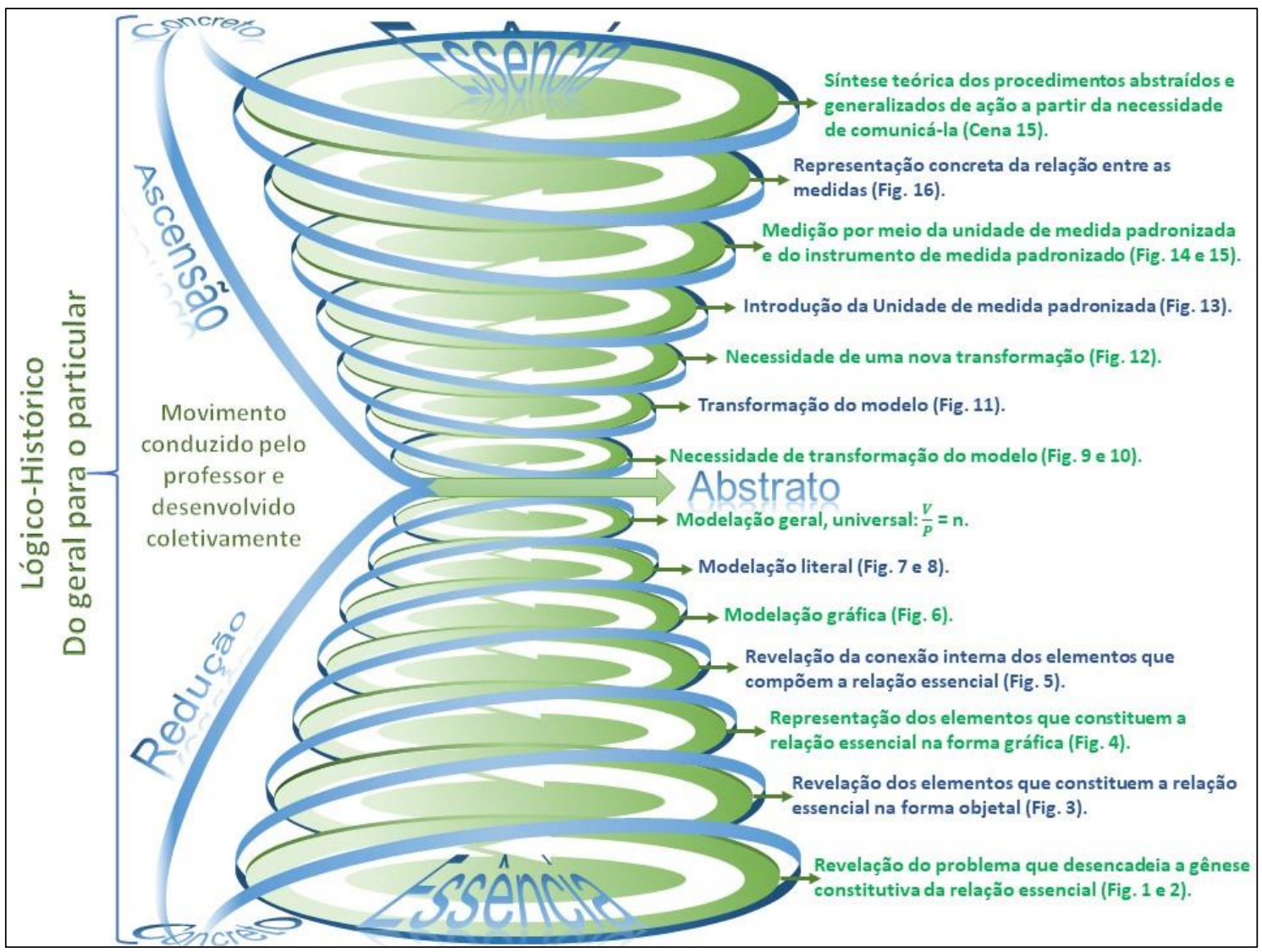

Fonte: Elaboração nossa (2020).

A partir da Situação Desencadeadora de Aprendizagem intitulada Um dia na vida de Artur, na primeira ação de estudo, revelamos a relação essencial do conceito de ângulo, mediante o movimento real do personagem Artur e por meio do corpo dos estudantes. Na sequência, representamos os movimentos reais na forma objetal por meio de leques decorativos. O movimento de rotação em torno do ponto central do leque foi abstraído por meio de elementos geométricos que compõem o ângulo. Tais significações permitiram responder o primeiro e o segundo problema desencadeador.

A partir do terceiro problema desencadeador, modelamos a relação essencial nas formas gráfica e literal (algébrica) na segunda ação de estudo. Os modelos, inicialmente particulares, refletiam as relações de divisibilidade e multiplicidade entre as medidas da volta completa, as unidades de medida, e a quantidade de vezes que as unidades de medida cabiam na volta completa. 
Portanto, revelamos a célula do conceito de número. Neste contexto de reflexões, surgiu o seguinte questionamento: é possível pensar o ensino de uma grandeza sem o conceito de número? Movidos por este questionamento, a partir da relação de divisibilidade e multiplicidade, ao término da segunda ação de estudo, atingimos a abstração máxima da relação essencial do conceito de número na forma geral, pois modelos particulares nos limitam a operar apenas em casos particulares.

No início da terceira ação de estudo, deparamo-nos com outra necessidade, a transformação do modelo. Assim, atingimos a unidade de medida atualmente aceita universalmente.

Dessa forma, com o modelo transformado e suprida a necessidade do número natural e racional na forma fracionária, avançamos para a resolução da medição do ângulo de inclinação da rampa. A medição foi possível a partir das transformações do modelo geral/universal. Ao suscitarmos a necessidade do número para exprimir o resultado da medição, emergiu outro questionamento: é possível pensar o conceito de número em nível teórico, desconsiderando como base fundante as relações entre grandezas?

Ao pensarmos o ensino do conceito de número a partir da grandeza ângulo, em nível teórico, operamos com o movimento de redução do concreto ao abstrato na primeira e segunda ação de estudo, bem como ascendemos do abstrato ao concreto mental na terceira e quarta ações de estudo.

A fim de atingir a síntese das múltiplas determinações, mesmo que provisória, propusemos um quinto momento a partir da necessidade de comunicar o conhecimento produzido. Desse modo, evidenciamos o processo de generalização das ações.

\section{Considerações finais}

Os resultados da investigação sobre o desenvolvimento do pensamento matemático em nível teórico, mediado pelo conceito de número a partir da grandeza ângulo, indicam que a dificuldade de compreensão deste conceito pode ser superada pela organização de seu ensino de modo a possibilitar aos 
estudantes a compreensão da essência do conceito e a dinâmica das interrelações que o determinam.

A partir destas relações é que se torna possível conceber o procedimento geral de ação, no âmbito das necessidades vivenciadas ao longo do desenvolvimento histórico da humanidade, até atingir as unidades de medida e os instrumentos padronizados tal como compreendemos atualmente. Ao conceber o ângulo como grandeza, cuja gênese incide no movimento de rotação em torno de um ponto fixo (vértice), possibilitamos a compreensão de que sua medição não ocorre pelo comprimento da distância de suas extremidades, uma vez que as semirretas (ou vetores) delimitam o início e o fim de um movimento cuja existência só é possível na imagem ideal, e não por meio da superfície.

Concluímos que dar condições à aprendizagem de conceitos científicos e ao desenvolvimento do pensamento teórico torna-se possível, quando organizamos o ensino de modo que suscitem as relações essenciais dos conceitos no contexto de seu sistema conceitual, em torno de sua essência, seu núcleo.

Para tanto, o movimento conceitual em torno da essência foi organizado do geral para o particular, por meio dos procedimentos de redução e ascensão, pautados nas quatro ações de estudo, contexto no qual a unidade do lógico-histórico encarna a necessidade humana em seu estágio mais atual.

Ao pensarmos o ensino do conceito de ângulo, nós o concebemos como uma grandeza que possibilita a medição da quantidade do movimento de rotação e, consequentemente, a medida do ângulo de inclinação, e não como mera característica dos polígonos. Em que pese tal importância, não deve ser tomada como ponto de partida para o seu ensino em nível teórico.

Ao finalizarmos a síntese anteriormente apresentada e refletirmos sobre o caminho transcorrido até este momento na investigação, encontramos algumas respostas que nos permitirão avançar nas reflexões, bem como na compreensão da Situação Desencadeadora de Aprendizagem, no âmbito da Atividade Orientadora de Ensino, como possibilidade de superação do ensino tradicionalmente desenvolvido no Brasil. 


\section{Referências}

ARAUJO, E. S. Atividade orientadora de ensino: princípios e práticas para organização do ensino de matemática. Revista Paranaense de Educação Matemática, v. 8, 2019. Disponível em:

http://rpem.unespar.edu.br/index.php/rpem/article/view/1822. Acesso em: 17 mar. 2021. DOI: https://doi.org/10.33871/22385800.2019.8.15.123-146.

BECKER, F.; ROSA, J. E. Ângulo - do abstrato ao concreto. GeoGebra. 2020.

Disponível em: https://www.geogebra.org/m/ms5aqvqx. Acesso em: 23 nov. 2020.

CARAÇA, B. J. Conceitos fundamentais da matemática. Lisboa: Tipografia Matemática, 1951.

DAVÍDOV, V. V. Tipos de generalización en la enseñanza. 3. ed. Habana: Editorial Pueblo y Educación, 1982.

DAVÍDOV, V. V. La enseñanza escolar y el desarrollo psíquico. Moscú: Editorial Progreso, 1988.

DAVÍDOV, V. V. Análise dos princípios didáticos da escola tradicional e dos possíveis princípios do ensino em um futuro próximo. Trad. Rosa, J. E. e Damazio, A. In: LONGAREZI, A. M.; PUENTES, R. V. (Orgs.). Ensino desenvolvimental: antologia. Uberlândia: Edufu, 2017, p. 211-223, livro I. DOI: https://doi.org/10.14393/edufu-978-85-7078-433-9.

FRAGA, M. A. Significação do ângulo: indícios do conceito em atividades de localização. 2016. Dissertação (Mestrado em Educação) - Universidade de São Paulo, 2016. Disponível em: https://www.teses.usp.br/teses/disponiveis/48/48134/tde18032019-155339/en.php. Acesso em: 23 nov. 2020. DOI: https://oi.org/10.11606/D.48.2019.tde-18032019-155339.

KOPNIN, P. V. A dialética como lógica e teoria do conhecimento. Rio de Janeiro: Civilização Brasileira, 1978.

MOURA, M. O. de (Coord.). Controle da variação de quantidades: Atividades de ensino. São Paulo: FEUSP, 1996.

MOURA, M. O. et al. A atividade orientadora de ensino como unidade entre ensino e aprendizagem. In: MOURA, M. O. (Org.). A atividade pedagógica na teoria histórico-cultural. Campinas: Autores Associados, 2016. p. 93-125.

NÓBRIGA, J. C. C.; SIPLE, I. Z. Livros Dinâmicos de Matemática. Revista do Instituto GeoGebra de São Paulo, v. 9, n. 2, p. 78-102, 2020. DOI:

http://dx.doi.org/10.23925/2237-9657.2020.v9i2p078-102. 
OLIVEIRA, N. M.; PANOSSIAN, M. L. Relações entre "situação desencadeadora" e "problema desencadeador". In: XXV SEMINÁRIO DE INICIAÇÃO CIENTÍFICA E TECNOLÓGICA DA UTFPR. Anais eletrônicos [...] Disponível em: https://eventos.utfpr.edu.br/sicite/sicite2020. Acesso em: 17 mar. 2021.

ROSA, J. E.; MATOS, C. F. Atividade orientadora de ensino e proposição davydoviana na organização do ensino de matemática. Obutchénie. R. de Didat. e Psic. Pedag. Uberlândia, MG. v.2, n.1, p. 69-91, jan./abr. 2018. Disponível em: http://www.seer.ufu.br/index.php/Obutchenie/article/view/42534. Acesso em: 17 dez. 2020. DOI: https://doi.org/10.14393/OBv2n1a2018-4. 